\title{
Insulin-like Growth Factor-1 (IGF-1) Gene Expression Is Enhanced under Hypothermia but Depressed under Additional Ischemic Stimulus
}

\author{
O-Yu Kwon ${ }^{1}$, Kisang Kwon ${ }^{2}$, Kweon $\mathrm{Yu}^{3}$ and Seung-Whan Kim ${ }^{4, \dagger}$ \\ ${ }^{I}$ Department of Anatomy, College of Medicine, Chungnam National University, Daejeon 301-747, Korea \\ ${ }^{2}$ Department of Biomedical Laboratory Science, College of Health \& Welfare, \\ Kyungwoon University, Gumi 730-739, Korea \\ ${ }^{3}$ Korea Research Institute of Bioscience \& Biotechnology, Daejeon 305-806, Korea \\ ${ }^{4}$ Department of Emergency Medicine, College of Medicine, Chungnam National University, \\ Daejeon 301-747, Korea
}

\begin{abstract}
There are several studies that show hypothermia improves cellular ischemia damages on experimental and clinical bases. However, its exact molecular mechanisms are unclear. In this study, we demonstrate that hypothermia induced insulin-like growth factor 1 (IGF1) gene expression, and its expression was dramatically decreased under ischemic insults. It was also demonstrated that hypothermia activated endoplasmic reticulum (ER) stress sensors especially both the phosphorylation of eIF2 $\alpha$ (eukaryotic translation initiation factor 2 alpha) and ATF6 (activating transcription factor-6) proteolytic cleavage. However, the factors of apoptosis and autophagy were not associated with hypothermia. We suggest that hypothermia-treated IGF1 gene expression after ischemia may show a good possibility for the development of treatments and diagnostic methods in cerebral ischemic damages.
\end{abstract}

Key Words: Insulin-like growth factor 1 (IGF1), Hypothermia, Ischemia, Endoplasmic reticulum (ER) stress sensor

Ischemic stress in the brain can induce the bimodal expression of a selective gene by the specific time interval. For example, in the acute stage of ischemic stimulus, the early gene is induced immediately, and this is followed by the induction of heat shock proteins, apoptotic genes, and inflammatory cytokines. The inhibition of GRP78 (78 kDa glucose-regulating protein) in the brain has a role to mediate neuronal cell death while the induction of BIX (BiP, binding immunoglobulin protein, inducer $\mathrm{X}$ ) is related to induce certain sequence of mediating neuronal survival (Kudo et al., 2008). The involvement of protection gene to ischemic injury,

*Received: March 13, 2015 / Revised: May 6, 2015

Accepted: May 7, 2015

${ }^{\dagger}$ Corresponding author: Seung-Whan Kim. Department of Emergency Medicine, College of Medicine, Chungnam National University, Daejeon 301-747, Korea

Tel: +82-42-280-8101, Fax: +82-42-280-8082

e-mail: emdfire@hanmail.net

(c) The Korean Society for Biomedical Laboratory Sciences. All rights reserved. such as those for heat shock protein, might be a molecular mechanism playing some part in tolerance mechanism in ischemic injury. Certain gene expression may be an important therapeutic target in ischemic injury. The expression of endoplasmic reticulum (ER) stress-related molecules has a partially important role to favorable ER stress response to transient ischemic injury (Yagita et al., 2008). The alteration of ER stress-related molecule transducers' distribution brings them in contact with appropriate molecular targets leading to gene expression change (Yamaguchi et al., 2007). If certain genes that are involved in the recovery from ischemia can be selected, these would be applied to therapeutic drug discovery for the cure of cerebral hypoxia (Mehta et al., 2007). In the near future, the therapy of hypothermia should consider the neuroprotective effect of it to enhance the therapeutic outcome from brain ischemia in both animals and humans (Miyazawa et al., 2003; Yanamoto et al., 2001; 
Kawai et al., 2000; Holzer et al., 2002; Bernard et al., 2002). Further studies about molecular chaperone in hypothermia treatment after ischemic insult will provide valuable information for the basic mechanism of neuroprotective pathogenesis after ischemia (Nielsen et al., 2013). From previous studies the cellular response to hypothermia results in altered gene expression and decreased oxygen/ATP consumption, however, the detailed intracellular mechanism is unknown (Ning et al., 2002). Further study is required to delineate the precise mechanisms of how hypothermia prevents neuronal cell death. Our previous studies (data not shown) using the differential display (DD)-PCR experiment with GeneFishing DEG premix kit (Seegene Co.), have shown that hypothermia increased the expression of insulin-like growth factor 1 (IGF1, somatomedin C) gene. It has predominant trophic roles in fetal growth and development (Agrogiannis et al., 2014). As far as we know, no studies have demonstrated the relationship between the hypothermia and intracellular signaling. Here, we tested whether the expression of IGF1 was associated with hypothermia, ischemia, ER stress, and especially ER stress signaling.

PC12 cells were cultured on collagen-coated flasks in 85\% RPMI 1640 supplemented with 25 mM HEPES buffer, $10 \%$ heat-inactivated horse serum and $5 \%$ heat-inactivated fetal bovine serum, $2 \mathrm{mM}$ L-glutamine, $1 \mathrm{mM}$ sodium pyruvate, $1 \mathrm{~g} / \mathrm{l} \mathrm{D}(+)$-glucose, and antibiotics: $25 \mu \mathrm{g} / \mathrm{ml}$ streptomycin and $25 \mathrm{U} / \mathrm{ml}$ penicillin at $37^{\circ} \mathrm{C}$ in a $5 \% \mathrm{CO}_{2}$ atmosphere. Total RNA from cultured cells was extracted using an RNA isolation reagent (TRI-Reagent Ambion, Austin, USA). RT-PCR using the forward primer F (5'AGTGGTGGCCACTAATGGAG-3') and reverse primer R (5'-TCTTTTGTCAGGGGTCGTTC-3') for BiP; F (5'GGGAGTCTTGTCGTGGAATTG-3') and R (5'-TGCTTTCCAAGACGGCAGA-3') for calnexin; F (5'-CAGGATTTGCCCTATCCAGA-3') and R (5'-GTCATTCCGTTCCTTCTCCA-3') for PDI; F (5'-GGCATTGTGGATGAGTGTTG-3') and R (5'-GTCTTGGGCATGTCAGTGTG-3') for IGF1; F (5'-TCAGCTTCGACACCAATGAG-3') and R (5'-GTATCCTCGGGACCGGTTAT-3') for CIRBP; F (5'-TTACCTCCACCAGCAGGAAC-3') and R (5'-ACCACCTCTCTGTGCAATCC-3') for Bak1; F (5'-AAGCTGCACAGCGGGGCTAC-3') and R (5'-CAGATGCCGGTTCAGGTACT-3') for Bcl2; F (5'-GCCTGTCCTGGATAAGACCA-3') and R (5'-GTTCACCAGCAGGAAGAAGG-3') for LC3; F (5'-GTGCTCCTGTGGAATGGAAT-3') and R (5'-GCTGCACACAGTCCAGAAAA-3') for Beclin; F (5'ACATCAAATGGGGTGATGCT-3') and R (5'-AGGAGACAACCTGGTCCTCA-3') for $\beta$-actin were performed
A

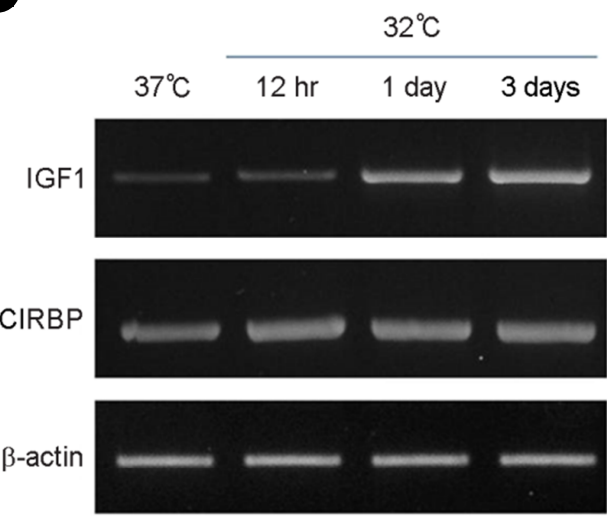

B

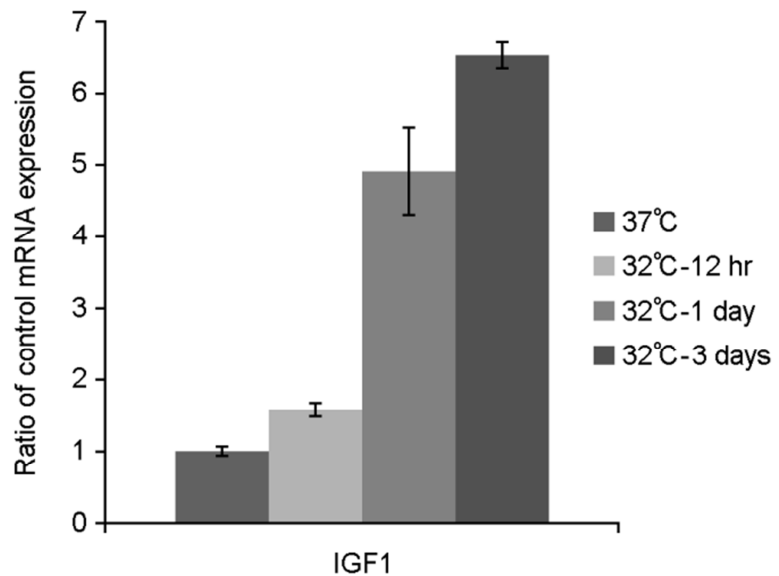

Fig. 1. Hypothermia increases IGF1 mRNA expression. $\mathrm{PC} 12$ cell were incubated under control condition $\left(37^{\circ} \mathrm{C}\right)$ or hypothermia $\left(32^{\circ} \mathrm{C}\right)$ for $12 \mathrm{hrs}$ and $1 \sim 3$ days. The experiments were performed three times, and representative results are shown (A) and the results represent the average (B), with control condition time-dependently like as each hypothermic situation. Hypothermia response was confirmed by increased expression of CIRBP mRNA, which is a positive marker. IGF1; insulin-like growth factor 1, CIRBP; cold-induced RNA-binding protein. 


\section{(A)}

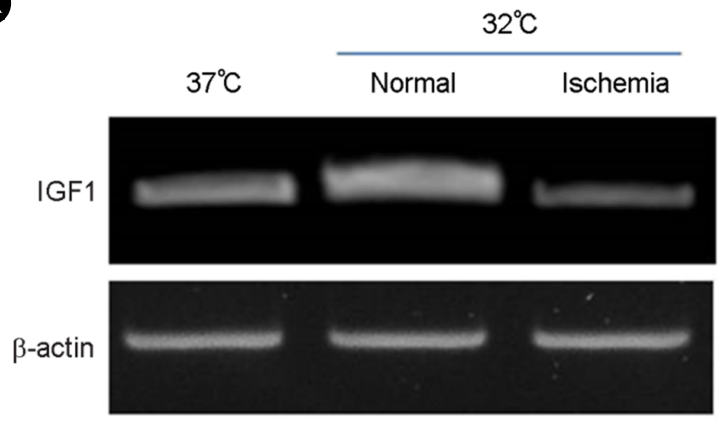

B

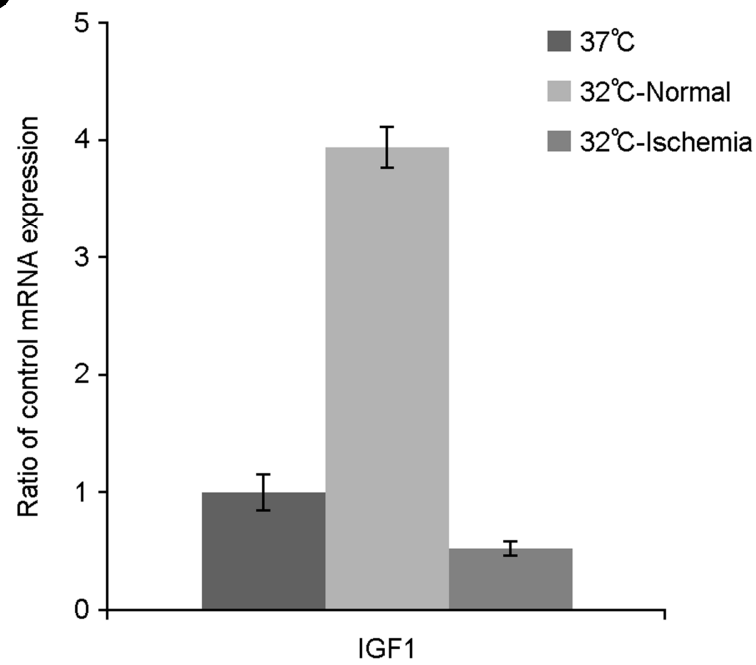

Fig. 2. Hypothermia decreases IGF1 mRNA expression during the ischemia. $\mathrm{PC} 12$ cells were incubated under control conditions $\left(37^{\circ} \mathrm{C}\right)$, hypothermia $\left(32^{\circ} \mathrm{C}\right)$, and ischemia under hypothermia $\left(32^{\circ} \mathrm{C}\right)$ for one day, respectively. The experiments were performed three times, and representative findings are shown (A) and results represent the average (B). IGF1; insulin-like growth factor 1 .

for 30 cycles $\left[94^{\circ} \mathrm{C}\right.$ for $30 \mathrm{~s} ; 58^{\circ} \mathrm{C}$ for $30 \mathrm{~s}$; and $72^{\circ} \mathrm{C}$ for $1 \mathrm{~min}$ (but $10 \mathrm{~min}$ in the final cycle)] with Taq DNA polymerase. Western blotting detection system kit (Amersham, Uppsala, Sweden) was used for ATF6 fragmentation and phosphorylation of eIF $2 \alpha$. eIF $2 \alpha-P$ antibody and goat antiactin antibody were purchased from Santa Cruz Biotechnology (Santa Cruz, CA, USA). Mouse anti-ATF6 antibody was obtained from Imgenex (San Diego, CA, USA).

$\mathrm{PC} 12$ cells were incubated under control conditions $\left(37^{\circ} \mathrm{C}\right)$ or hypothermia $\left(32^{\circ} \mathrm{C}\right)$ for $12 \mathrm{hrs}, 1$ or 3 day, respectively. The expression of the cold-induced RNA-binding protein
(CIRBP) was used as a positive control (Al-Fageeh and Smales, 2009). We found that the expression of IGF1 was increased slightly about 2 fold by 12 hrs-hypothermia compared to its control; but the exposure to 1 day-hypothermia induced by about 5 folds and 3 days-hypothermia treatment increased about 6.5 folds in gene expression (Fig. 1). We surmised from the result shown in Fig. 1, that hypothermia obviously induced IGF1 gene expression, in the other words IGF1 gene expression was hypothermia dependently upregulated. We determined IGF1 gene expression in both, cells treated with hypothermia alone and cells treated with hypothermia together with ischemia, to verify whether hypothermia induced cells were related to ischemia. As shown in the Fig. 2, IGF1 gene expression under hypothermia condition increased comparing to its control as the same result with Fig. 1. At this point, there is no data to support that IGF1 gene expression is related to ischemia. However, the result shown in Fig. 2 demonstrated that hypothermia severely down-regulated IGF1 mRNA expression under additional ischemia approximately half-expression as compared to the control. After all, the IGF1 gene expression is reduced to about $1 / 8$ by hypothermia-ischemia treatment than hypothermia treatment only. To understand associated pathways, we have tested whether hypothermia controlled ER chaperones (BiP, calnexin and PDI) (Braakman and Bulleid, 2011), the downstream-factors of ER stress sensors (Xbp1, eIF2 $\alpha$ and ATF6) (Lee and Ozcan, 2014), apoptosisassociated factors (Bak1 and Bcl-2) (Lovat et al., 2003) and autophagy-associated factors (LC3 and beclin) (Jin and Klionsky, 2014). Cells exposed to hypothermia had no changes in ER chaperones gene expression (Fig. 3A), apoptosis-associated factors (Fig. 3D) and autophagyassociated factors (Fig. 3E). Although no spliced Xbp1 (Fig. 3B) was observed, both the cleavage of ATF-6 and phosphorylation of eIF2 $\alpha$ was apparently increased (Fig. $3 \mathrm{C})$. The result of Fig. 3 showed that hypothermia controlled IGF1 mRNA expression through the activation of down-stream ER stress sensors, i.e. cleavage of ATF-6 and phosphorylation eIF2 $\alpha$, but not ER chaperones.

In summary, the present study was the first to demonstrate that hypothermia induced IGF1 mRNA. Additionally, its expression was further decreased to less than control levels 
A

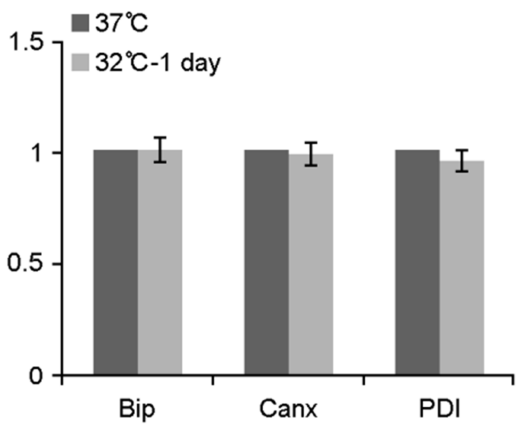

B

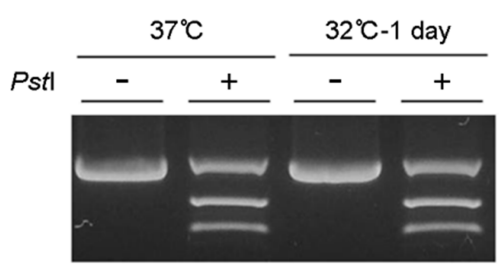

$\boldsymbol{E}$

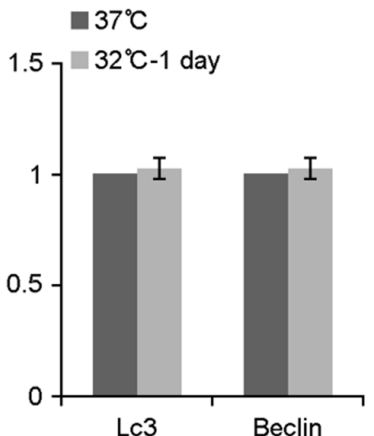

Fig. 3. Effect of hypothermia on gene expression of ER chaperones, Xbp1 mRNA splicing, ER stress sensors, apoptosis-associated factors and autophagy-associated factors. $\mathrm{PC} 12$ cells were incubated under control conditions $\left(37^{\circ} \mathrm{C}\right)$ or hypothermia $\left(32^{\circ} \mathrm{C}\right)$ for one day. Gene expressions were determined by RT-PCR (A, D, E). The product of Xbp1-Pst1 digestion was subjected to electrophoresis on the agarose gel (B). Cleavage of ATF-6 and phosphorylation of elF2 $\alpha$ were assessed by Western blotting (C). The experiments were performed three times, and results represent the average, and representative findings are shown. BiP; binding immunoglobulin protein, Canx; calnexin, PDI; protein disulfide isomerase, ATF6; activating transcription factor 6, p-elF2 $\alpha$; phosphorylation of eIF2 $\alpha$, Bak1; BCL2-antagonist/killer 1, Bcl-2; B-cell lymphoma 2, LC3; microtubule-associated protein 1 light chain 3 $\alpha$, beclin; coiled-coil myosin-like BCL2-interacting protein.

under conditions of ischemia. IGF1 gene expression by hypothermia was associated with unfolded protein response; and activation of ER stress sensors, especially higher phosphorylation of eIF2 $\alpha$ and ATF6 cleavage but unchanged ER chaperone expression. No alternative mRNA expression of apoptosis- and the autophagy-associated factor was observed in cells treated with hypothermia. Our findings suggested that hypothermia decreased IGF1 gene expression under ischemia, which may provide new insight into the possibility of hypothermia treatment for ischemia, and may help in the development of novel methods for easy and quick diagnosis of neurodegenerative disorders, including ischemia and hypoxia.

\section{Acknowledgements}

This work was supported by a National Research Foundation of Korea Grant funded by the Korea Government (MEST) (NRF-2010-0009806).

\section{Conflict of interest}

We have no conflict of interest and any copyright constraints.

\section{REFERENCES}

Agrogiannis G, Sifakis S, Patsouris ES, Konstantinidou AE. Insulinlike growth factors in embryonic and fetal growth and skeletal development. Mol Med Rep. 2014. 10: 579-584.

Al-Fageeh MB, Smales CM. Cold-inducible RNA binding protein 
(CIRP) expression is modulated by alternative mRNAs. RNA. 2009. 15: 1164-1176.

Bernard SA, Gray TW, Buist MD. Treatment of comatous survivors of out-of-hospital cardiac arrest with induced hypothermia. N Engl J Med. 2002. 346: 557-563.

Braakman I, Bulleid NJ. Protein folding and modification in the mammalian endoplasmic reticulum. Annu Rev Biochem. 2011. 80: 71-99.

Holzer M, Sterz F, Darby JM. Mild therapeutic hypothermia to improve the neurologic outcome after cardiac arrest. N Engl J Med. 2002. 346: 549-556.

Jin M, Klionsky DJ. Regulation of autophagy: Modulation of the size and number of autophagosomes. FEBS Lett. 2014. 588: 2457-2463.

Kawai N, Okauchi M, Morisaki K, Nagao S. Effects of delayed intraischemic and postischemic hypothermia on a focal model of transient cerebral ischemia in rats. Stroke. 2000. 31: 1982 -1989 .

Kudo T, Kanemoto S, Hara H, Morimoto N, Morohara T, Kimura $\mathrm{R}$, Tabira T, Imaizumi K, Takeda M. A molecular chaperone inducer protects neurons from ER stress. Cell Death Differ. 2008. 15: 364-375.

Lee J, Ozcan U. Unfolded protein response signaling and metabolic diseases. J Biol Chem. 2014. 289: 1203-1211.

Lovat PE, Oliverio S, Corazzari M, Ranalli M, Pearson AD, Melino
G, Piacentini M, Redfern CP. Induction of GADD153 and Bak: novel molecular targets of fenretinide-induced apoptosis of neuroblastoma. Cancer Lett. 2003. 197: 157-163.

Mehta SL, Manhas N, Raqhubir R. Molecular targets in cerebral ischemia for developing novel therapeutics. Brain Res Rev. 2007. 54: 34-66.

Miyazawa T, Tamura A, Fukui S, Hossmann KA. Effect of mild hypothermia on focal cerebral ischemia. Review of experimental studies. Neurol Res. 2003. 25: 457-464.

Nielsen N, Wetterslev J, Cronberg T, Erlinge D, Gasche Y, Hassager C, Horn J, Hovdenes J. Targeted temperature management at 33 versus 36 after cardiac arrest. N Engl J Med. 2013. 369: 2197-2206.

Ning XH, Chen SH, Xu CS, Li L, Yao LY, Qian K, Krueger JJ, Hyyti OM, Portman MA. Hypothermic protection of the ischemic heart via alterations in apoptotic pathways as assessed by gene array analysis. J Appl Physiol. 2002. 92: 2200-2207.

Yagita Y, Sakoda S, Kitagawa K. Gene expression in brain ischemia. Brain Nerve. 2008. 60: 1347-1355.

Yamaguchi T, Sakurai M, Abe K, Matsumiya G, Sawa Y. Impact of the endoplasmic reticulum stress response in spinal cord after transient ischemia. Brain Res. 2007. 1169: 24-33.

Yanamoto H, Nagata I, Niitsu Y. Prolonged mild hypothermia therapy protects the brain against permanent focal ischemia. Stroke. 2001. 32: 232-239. 